Выявленные гистологические изменения в компонентах трубчатых костей могут способствовать прогнозированию результатов лечения деформаций скелета, а также их осложнений.

При экспериментальном гипопаратиреозе происходят резко выраженные изменения в хрящевых элементах, проявляющиеся вакуолизацией хондроцитов.

На основе результатов морфологических методов исследования раскрыта динамика формирования трубчатых костей, а также установлены закономерности окостенения трубчатых костей на фоне гипопаратиреоза.

В результате подробного анализа морфологических изменений подготовлены практические рекомендации для разработки профилактических мероприятий при деформации конечностей на фоне сниженной функции околощитовидной железы.

Заключение. Таким образом, при экспериментальном гипофункции околощитовидной железы в костной ткани происходит значительные морфологические сдвиги, которые немаловажные влияние оказывает у растущему организму. В начальных периодах эксперимента отмечается очаговые дистрофии хондроцитов и определяется частичные торможения остеогенеза на поверхности ростковой зоны. В более отдаленном периоде эксперимента выявляась дедифференцировка поверхностного и переходного слоев гиалинового хряща в волокнистую ткань. В глубоких слоях хряща отмечались признаки снижения пролиферативных процессов и нарастание дегенеративных, что приводило к извращению остеогенеза на поверхности зоны роста.

$$
* * *
$$

1. «Peculiarities of the hypofunction of the parathyrioid gland in rats on the morphological formation of bone tissue» «European journal of molecular \&Clinical medicine» Volume7, Issue 3 2020г 3549-3559cт

2. «Morphological structure of the thigh - bone in white rats with action of hypothireoid condition» «Современная медицина: Новые подходы и актуальные исследования» Москва, 2017г №6(5) 8084стр

3. Маргорин Е.М. Топографо-анатомические особенности новорожденного. - Ленинград, Медицина, 1977. - 277 c.

4. Матвеева Е. Л., Лунева С. Н., Палошова И. А. Результаты хроматографического и электрофоретического раздела гликозаминогликанов сыворотки крови, суставного хряща и костной ткани //Гений ортопедии. -Россия. -2002. -№4. -С. 92-94.

5. Seze S., Solnica J., Mitrovic D. et al. Joint and bone disorders and hypoparathyroidism in hemochromatosis. Semin. Arthritis. Rheum. 1972; 2: 71-94.

6. ShobackD. Clinical practice. Hypoparathyroidism. N. Engl. J. Med. 2008; 359: 391-403.

7. Testini M., Gurrado A., Lissidini G., Nacchiero M. Hypoparathyroidism after total thyroidectomy // Minerva Chir. 2007. V. 62(5). P. 409-415.

8. ThakkerR.V. Genetics of endocrine and metabolic disorders: parathy-roid. Rev. Endocr. Metab. Disord. 2004; 5: 37-51.

\title{
Сметанин В.H. \\ Некоторые аспекты заболеваемости инфекций, связанных с оказанием медицинской помощи
}

Рязанский государственный медииинский университет имени акад. И.П. Павлова

(Россия, Рязань)

doi 10.18411/gq-31-03-2021-05

idsp sciencerussia-31-03-2021-05

\section{Аннотация}

Проблема профилактики и лечения инфекций, связанных с оказанием медицинской помощи (ИСМП), остается одной из самых актуальных в мире, затрагивая от 5 до $20 \%$ пациентов медицинских учреждений. Важность

ИСМП определяется их распространенностью, негативными последствиями для здоровья и жизни пациентов, халатностью медицинских работников, а также 
повышением затрат на медицинское обслуживание, что приводит к увеличению потребности в дополнительных средствах для медучреждений.

Ключевые слова: инфекции, оказание медицинской помощи, заболеваемость, медицинское учреждение, медицинский работник.

Инфекции, связанные с оказанием медицинской помощи (ИСМП), - это инфекции, которые возникают во время получения медицинской помощи и развиваются в медицинских учреждениях, впервые появляются через 48 часов или более после поступления в больницу [2]. Многочисленные исследования показывают, что наиболее распространенными типами нежелательных явлений, влияющих на госпитализированных пациентов, являются нежелательные лекарственные препараты, ИСМП и хирургические осложнения. Выявлено, что по контролю и профилактике заболеваний в России около 1,7 миллиона госпитализированных пациентов ежегодно приобретают ИСМП во время лечения других заболеваний, из них более 98000 пациентов (каждый 17) умирают. Исследования показывают, что простые процедуры инфекционного контроля, такие как мытье рук спиртосодержащим средством могут помочь предотвратить ИСМП и спасти жизни, снизить заболеваемость и минимизировать затраты на здравоохранение. Регулярные образовательные мероприятия для специалистов здравоохранения могут помочь изменить методы мытья рук, чтобы предотвратить распространение инфекции. В поддержку данного метода ВО3 разработала руководящие принципы по распространению практики мытья рук. Гигиена рук и соблюдение правил асептики перед уходом за уязвимым пациентом могут уменьшить временное носительство и перенос микроорганизмов. Защитные преимущества инфекционного контроля с использованием научно обоснованных практик рентабельны и многочисленны: они не только способствуют достижению наилучших результатов индивидуальной помощи пациентам, но и защищают медицинских работников, повышают осведомленность населения во всех медицинских учреждениях о проблемах инфекционного контроля и поддерживать высочайшие стандарты в медицине, что положительно способствует достижению нашей цели по обеспечению наилучших результатов для пациентов с ИМСП.

ИСМП способствуют увеличению заболеваемости и смертности, и вместе с тем чрезмерным расходам на медицинское обслуживание и увеличению продолжительности пребывания в больнице. Это имеет далеко идущие последствия для населения, приводя к широкому распространению патогенов с множественной лекарственной устойчивостью в больницах и распространению возникающих и повторно возникающих инфекций среди медицинских работников и населения.

ИСМП стали более распространенными, поскольку медицинское обслуживание претерпевает изменения, которые привели к широкому использованию инвазивных катетеров центральной линии, мочевых катетеров и аппаратов ИВЛ, что предрасполагает потенциальное увеличение пациентов с внутрибольничной инфекцией.

Помимо этого, сами медицинские работники подвержены риску заражения широким спектром инфекций, которые вызывают серьезные заболевания и случайные смерти. Несмотря на это, в немногих исследованиях изучалась заболеваемость, распространенность или уровень инфицирования, связанный с экспозицией, или рассматривались специфические для инфекции вмешательства, рекомендованные для обеспечения безопасности работников.

В связи с постоянной регистрацией на территории Российской Федерации инфекций, связанных с оказанием медицинской помощи, высоким экономическим ущербом и вредом для здоровья пациентов, был проведен ретроспективный эпидемиологический анализ заболеваемости, регистрируемой у населения города 
Рязанской области в течение 2016-2018 гг., изучены закономерности возникновения и распространения внутрибольничных инфекций.

Цель настоящего исследования - провести анализ инфекций, связанных с оказанием медицинской помощи в Рязанской области.

Материалы и методы. Материалами исследования является проведенный анализ статистических показателей заболеваемости ИСМП за 2016-2018 гг. в Рязанской области, включающий в себя определение частоты и структуры заболеваемости ИСМП при оказании медицинской помощи.

Результаты и обсуждение. В Рязанской области за 2016-2018 гг. в структуре заболеваемости ИСМП по форме № 2 и РЦ на первом месте находятся внутрибольничные пневмонии. На втором - послеоперационные инфекции, на третьем - гнойно-септические инфекции (ГСИ) новорожденных, на четвертом - ГСИ послеродового периода, инфекции мочевыводящих путей в структуре ИСМП составили пятое место, постинъекционные инфекции - шестое место, седьмое место занимают острые кишечные инфекции, а восьмое место - другие инфекционные заболевания $[1,6]$. Структура заболеваемости ИСМП по форме № 2 и по данным РЦ за 2016-2018 гг. представлена на рисунке 1 [3].

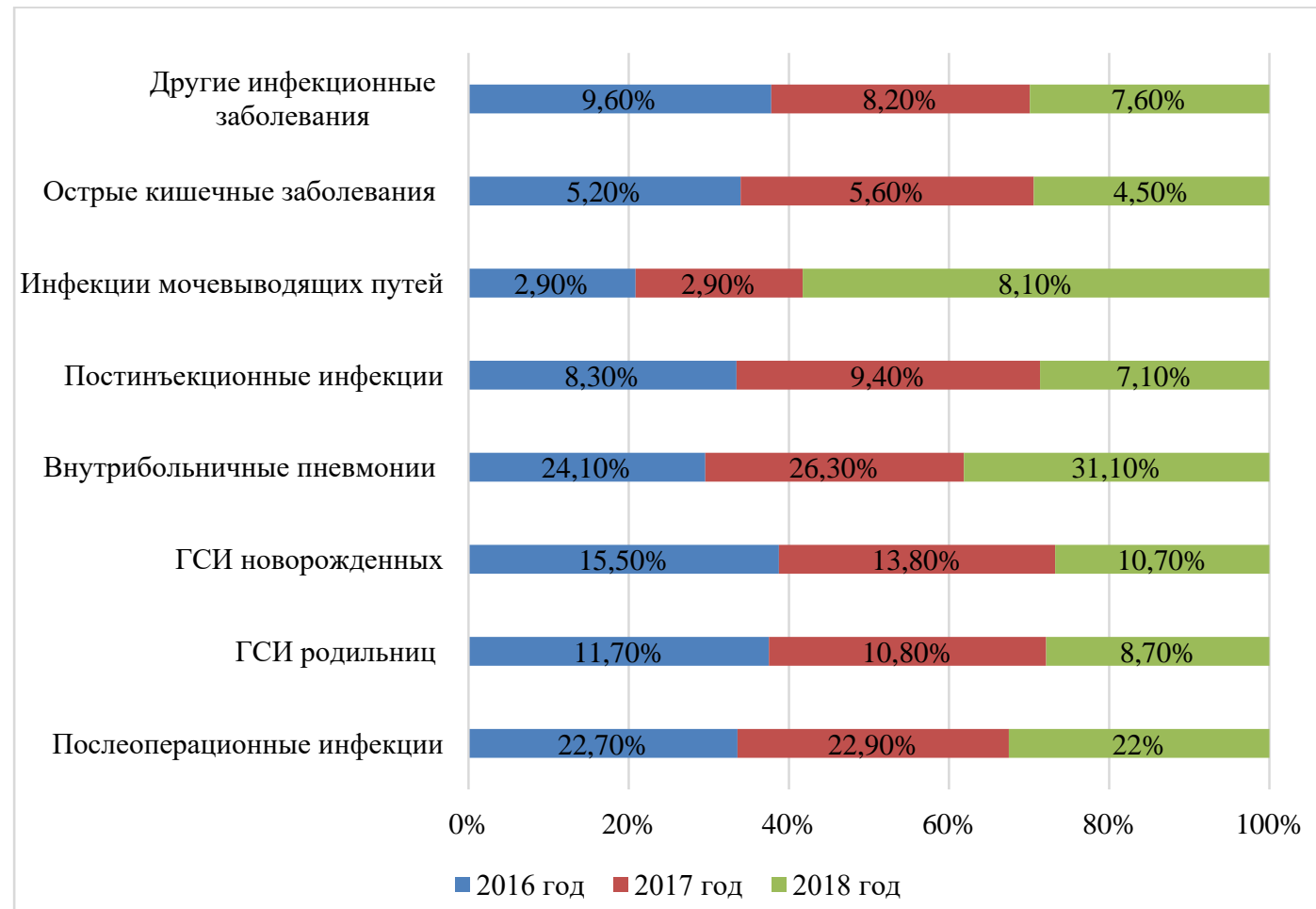

Рис. 1. Структура заболеваемости ИСМП за 2016-2018 г2. по данным формы № 2 и РЦ в Рязанской области, \%

По сравнению с 2016 г. в 2018 г. улучшилась регистрация инфекций мочевыводящих путей, их доля в структуре заболеваемости выросла до 8,1\%. Доля других инфекционных заболеваний в структуре ИСМП составила 7,6\%; постинъекционных инфекций - 7,1\%; острых кишечных инфекций - 4,5\%.

Также уменьшились показатели ГСИ новорожденных, составив в 2016 г. 15,5\%, в 2017 г. $-13,8 \%$, а в 2018 г. - 10,7\%. По итогу стоит сказать, что данный показатель в 2018 г. уменьшился на 4,8\% по сравнению с 2016 г. Вместе с тем отметим, что ГСИ родильниц уменьшились на $3 \%$. Полученные данные свидетельствуют о недостаточном учете такой нозологической формы, как инфекции кровотока, которые во многом определяют продолжительность пребывания в стационаре и высокую смертность. Количество зарегистрированных случаев других инфекций, например, из-за 
использования инвазивных устройств (заражение устройств) указывает на серьезную ошибку в регистрации ИСМП. В 2018 г. с введением новых форм отчётности впервые были зарегистрированы 20 случаев ИСМП, связанных с применением эндоскопических методов исследования. Отсутствует регистрация случаев ИСМП с переливанием крови и ее компонентов, что требует дополнительного изучения [4;5;7].

Основными причинами ИСМП являются неоптимальные методы инфекционного контроля и чрезмерное использование противомикробных препаратов. В долгосрочной перспективе снижение показателей ИМСП зависит от реализации профилактических стратегий, которые требуют изменения поведения и культуры. Эти меры должны осуществляться в рамках индивидуальной ответственности, сильной административной поддержки и доступа к актуальным национальным и местным данным.

Результаты проведенного анализа подтверждают влияние санитарных процедур на заболеваемость ИСМП, показывая, что медицинский персонал способен снизить риск инфекции, используя научно-обоснованные методы асептической работы, способствующие уменьшению проникновения эндогенных или экзогенных организмов через инвазивные медицинские устройства.

Выводы. На основании анализа распространенности ИСМП в Рязанской области полагаем, что необходимо дальнейшее улучшение эпидемиологического надзора, включающее в себя: обучение медицинского персонала принципам сбора, хранения и транспортировки клинического материала; повышение возможности полноценного микробиологического мониторинга инфекций ИСМП, особенно в амбулаторно-поликлинических организациях и хирургических отделениях. В отделениях интенсивной терапии для взрослых, нефрологических, неонатологических и педиатрических отделениях необходимы приоритетные усилия для улучшения практики, поскольку в этих отделениях повышен риск заражения пациентов с ИСМП из-за частого использования инвазивных устройств. Удаление отеков в послеродовых и хирургических палатах, улучшение соотношения медсестер и пациентов и принятие профилактических мер по снижению инфекций имеют решающее значение для снижения распространенности ИСМП в будущем.

Крайне важно, чтобы в больницах применялись эффективные стратегии лечения ИСМП, где медработники осознавали важность своей индивидуальной роли в профилактике ИСМП. Успех таких стратегий потребует культурного сдвига с упором как на институциональную, так и на индивидуальную ответственность, а также на соблюдение руководящих принципов, которые продвигают оптимальные методы инфекционного контроля и разумное использование противомикробных препаратов.

Представленные статистические данные свидетельствуют о том, что показатели ИМСП в Рязанской области несколько снизились за последние три года, что свидетельствует о необходимости контроля при инфекциях кровотока, пневмонии, связанной с аппаратом ИВЛ; инфекциях, не связанных с медицинскими устройствами в отделениях интенсивной терапии (ОИТ).

В связи с этим необходимо разработать эффективные способы улучшения глобального здравоохранения с целью снижения источников инфекций, связанных с оказанием медицинской помощи.

$$
* * *
$$

1. Агарев, А.Е. Инфекции, связанные с оказанием медицинской помощи в родовспомогательных учреждениях Рязанской области / А.Е. Агарев, Т.Д. Здольник, В.Н. Сметанин // Наука молодыхERUDITIO JUVENIUM. - 2017. - №2. - С. 225- 231.

2. Акимкин, В.Г. Оптимизация системы мер борьбы и профилактики инфекций, связанных с оказанием медицинской помощи в Российской Федерации / В.Г. Акимкин

3. Н.Б. Найговзина, А.Ю. Попова и др. // Вестник ВШОУЗ. - 2018. - № 1. - С. 17-26. 
4. Акимкин, В.Г. Инфекции, связанные с оказанием медицинской помощи (ИСМП): Информационный бюллетень / В.Г. Акимкин, А.В. Тутельян, О.А. Орлова, А.А. Голубкова, О.А. Квасова, Н.В. Сычева, Т.С. Скачкова. - М.: ФБУН ЦНИИ Эпидемиологии Роспотребнадзора, 2019. $-51 \mathrm{c}$.

5. Иванова, М.В. О необходимости изменения подходов к регистрации инфекций новорождённых, связанных с оказанием медицинской помощи, и внутриутробные инфекций / М.В. Иванова, А.Я. Миндлина, А.Б. Серебрий // Эпидемиология и вакцинопрофилактика. - 2019. - № 18(2). - С. 104112.

6. Котив, Б.Н. Характеристика этиологической структуры инфекции, связанной с оказанием медицинской помощи в многопрофильном стационаре / Б.Н. Котив, Б.Ю. Гумилевский, Е.Н. Колосовская, Л.А. Кафтырева, Е.С. Орлова, Ф.В. Иванов, А.И. Соловьева // Вестник Российской военной-медицинской академии. - 2020. - № 1 (69). - С. 7-11.

7. Смирнова, С.С. Внутриутробные инфекции новорождённых как маркер эпидемиологического благополучия в учреждениях родовспоможения. Эпидемиология и вакцинопрофилактика / С.С. Смирнова, А.А. Голубкова, А.В. Алимов, В.Г. Акимкин // Эпидемиология и Вакцинопрофилактика. - 2019. - № 5(18). - С. 42-49.

8. Ткаченко, А.К. К понятию «внутриутробное инфицирование и внутриутробная инфекция» / А.К. Ткаченко, О.Н. Романова, Е.М. Марочкина // Журнал Гродненского государственного медицинского университета. - 2017. - № 1(57). - С. 103-109.

\section{Черток Е.Д., Гудков В.М., Бакутина Ю.Ю. Ранняя диагностика железодефицитных состояний у детей-аллергиков}

ФГБОУ ВО «Воронежский государственный медицинский университет им. Н.Н. Бурденко» МЗ РФ

(Россия, Воронеж)

doi 10.18411/gq-31-03-2021-06

idsp sciencerussia-31-03-2021-06

\section{Аннотация}

Основной причиной развития анемии в детском возрасте является дефицит железа. Однако, диагноз железодефицитной анемии выставляется, как правило, только при выявлении изменений в гемограмме, а начальные стадии дефицита железа в виде сидеропенического синдрома остаются нераспознанными, и коррекция дефицита железа не проводится. Дефицит железа приводит к снижению иммунной защиты и развитию частых респираторных заболеваний, которые являются триггерным фактором возникновения обострений респираторных аллергических заболеваний (бронхиальная астма, аллергический ринит). Целью нашей работы была возможность выявления ранних признаков железодефицитного состояния у детей-аллергиков. Проведено исследование амбулаторных карт и анкетирование родителей 139 детей с различными аллергическими заболеваниями (бронхиальная астма, аллергический ринит, атопический дерматит). По результатам анкетирования признаки сидеропенического синдрома выявлены у 76,2\% детей. Частые респираторные заболевания отмечены у 62,4\% детей, которые характеризовались длительным субфебрилитетом (до 7-10 дней), затяжным кашлем и насморком. У большинства детей уровень гемоглобина был в пределах нормальных значений, однако зарегистрировано снижение среднего объема эритроцитов, что является достоверным признаком железодефицитного состояния. Рекомендуется обратить внимание участковых педиатров на тщательный сбор анамнеза и анализ гемограммы с целью выявления сидеропенического синдрома и своевременного проведения заместительной терапии препаратами железа.

Ключевые слова: Железодефицитное состояние, дети, сидеропенический синдром.

\section{Abstract}

The main cause of anemia in childhood is iron deficiency. However, the diagnosis of iron deficiency anemia is usually made only when changes in the hemogram are detected, and 